\title{
QUALITY ASSURANCE PROGRAM PLAN \\ FOR TRUPACT-II \\ GAS GENERATION TEST PROGRAM
}

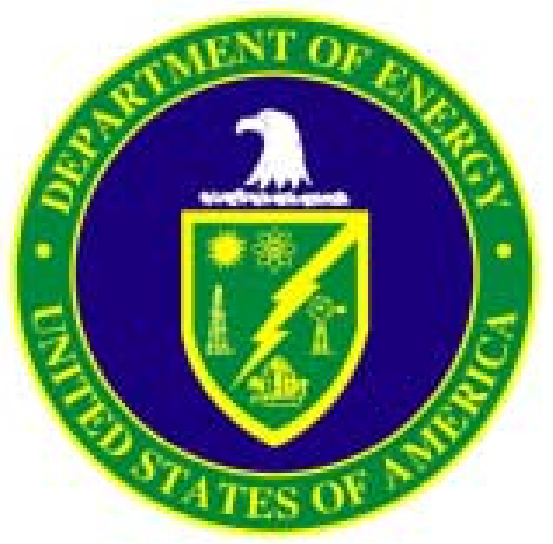

MARCH 2002

This document supersedes

DOE/WIPP 01-3187, Revision 0

\section{U. S. DEPARTMENT OF ENERGY CARLSBAD FIELD OFFICE}




\section{QUALITY ASSURANCE PROGRAM PLAN \\ FOR TRUPACT-II \\ GAS GENERATION TEST PROGRAM}

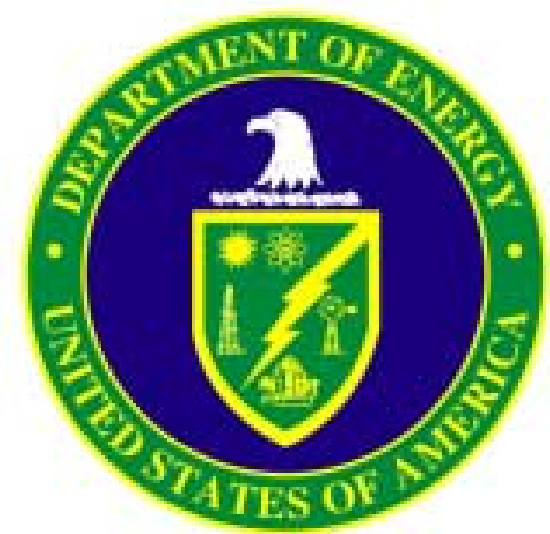

MARCH 2002

Prepared by: SIGNATURE ON FILE

Date:

M. A. Italiano, CBFO Transportation Manager

Approved by: SIGNATURE ON FILE

Date:

Assistant Manager, Office Of National TRU Programs

\section{U. S. DEPARTMENT OF ENERGY CARLSBAD FIELD OFFICE}




\section{TABLE OF CONTENTS}

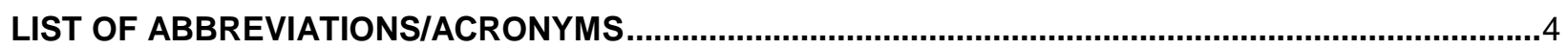

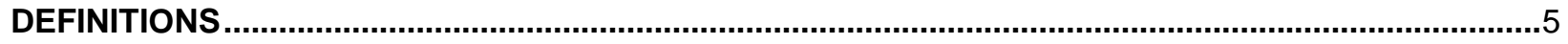

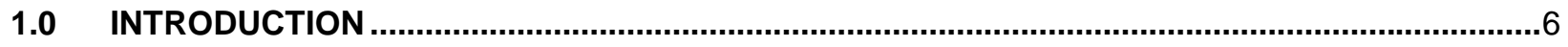

2.0 PROGRAM DESCRIPTION

2.1 PROGRAM ORGANIZATION

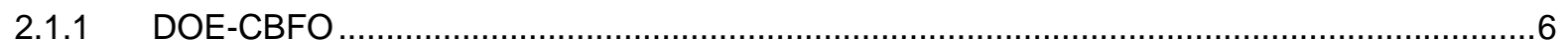

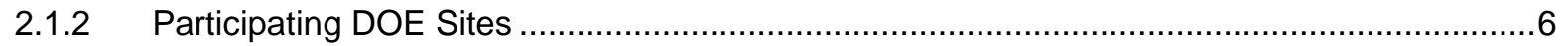

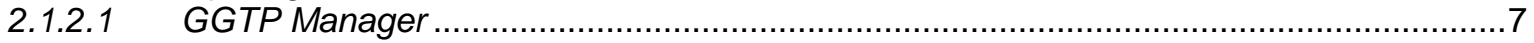

2.1.2.2 GGTP Technical Supervisor .............................................................................

2.1.2.3 GGTP Independent Technical Reviewer...........................................................

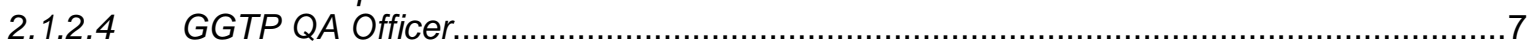

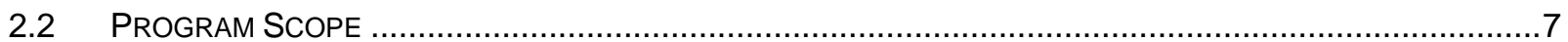

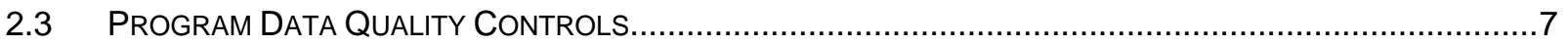

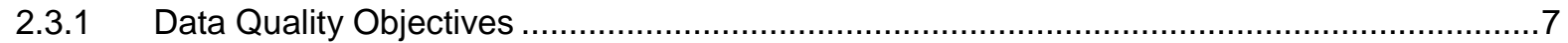

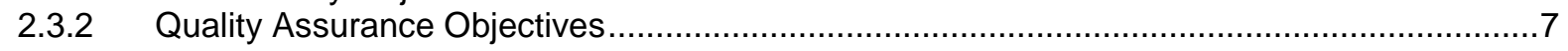

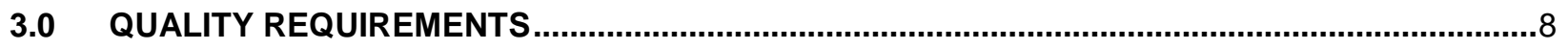

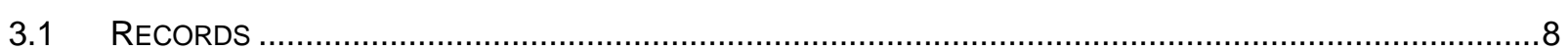

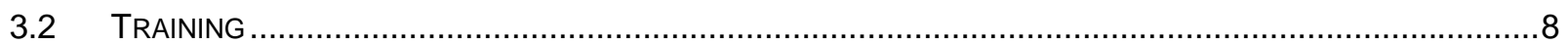

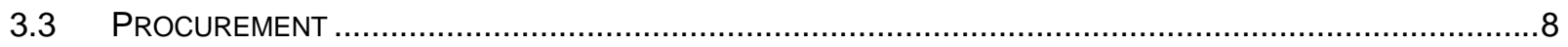

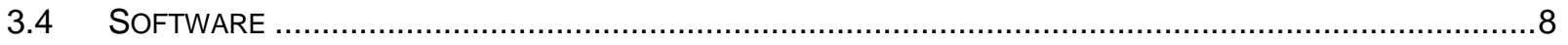

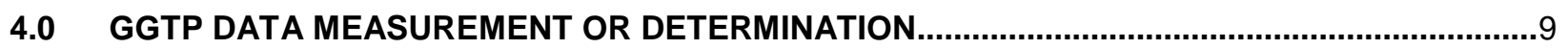

4.1 FLAMMABLE VOC CONCENTRATION IN CONTAINER HEADSPACE ...............................................

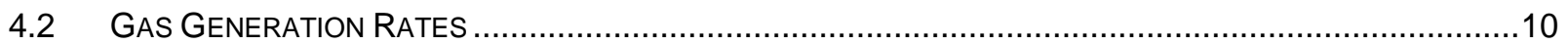

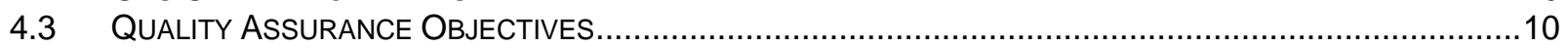

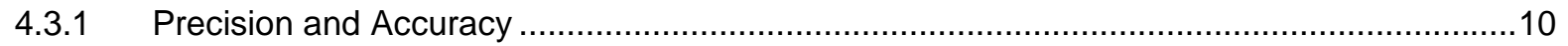

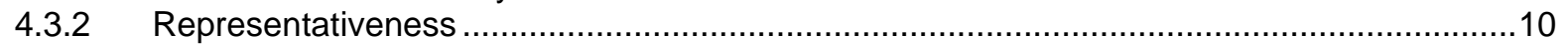

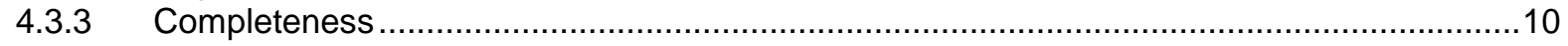

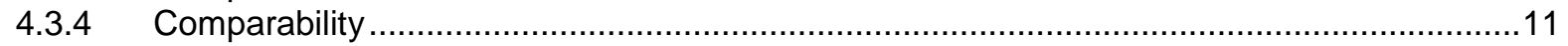

4.4 QC REQUIREMENTS FOR PROGRAM SAMPLING AND ANALYSIS .................................................11

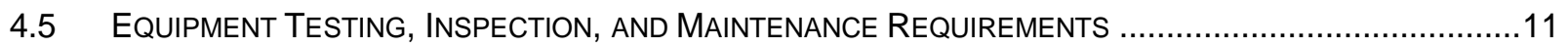

5.0 DATA MANAGEMENT, REDUCTION, REVIEW, VALIDATION, AND REPORTING ...................11

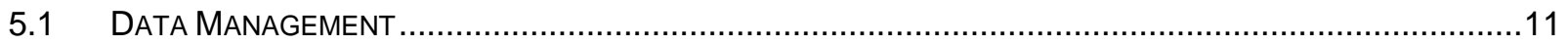

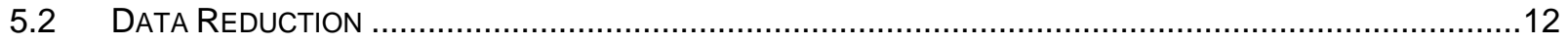

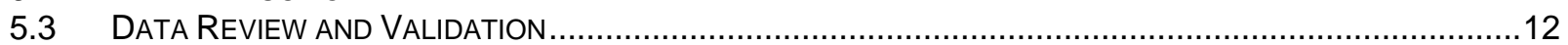

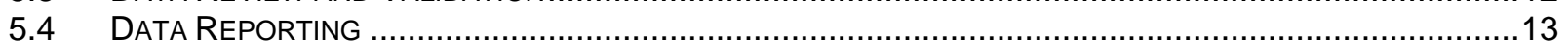

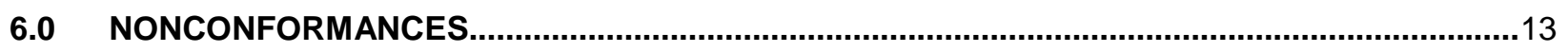

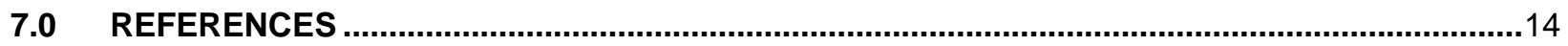




\section{ABBREVIATIONS/ACRONYMS}

CBFO Carlsbad Field Office

DOE U.S. Department of Energy

DQO data quality objective

GGTP Gas Generation Test Program (the Program)

ppm parts per million

PRQL program-required quantitation limit

QA quality assurance

QAO quality assurance objective

QAPD Quality Assurance Program Document

QAPjP Quality Assurance Project Plan

QAPP Quality Assurance Program Plan

QC quality control

TRAMPAC TRUPACT-II Authorized Methods for Payload Control

TRUPACT-II Transuranic Package Transporter-II

VOC volatile organic compound 


\section{DEFINITIONS}

Precision is a measure of mutual agreement among individual measurements of the same property, usually under prescribed similar conditions.

Accuracy is the degree of agreement between a measured value and an accepted reference or true value.

Representativeness is the degree to which sample data accurately and precisely represent a characteristic of a population, parameter variations at a sampling point, or an environmental condition.

Completeness is the percentage of measurements made that are judged to be valid measurements. The completeness goal is to generate a sufficient amount of valid data based on project needs.

Comparability is the degree to which one data set can be compared to another. Sample data should be comparable with other measurement data for similar samples and sample conditions. To evaluate comparability, the standards shall be analyzed to the same degree of accuracy and precision. 


\section{$1.0 \quad$ INTRODUCTION}

The Gas Generation Test Program (GGTP), referred to as the Program, is designed to establish the concentration of flammable gases and/or gas generation rates in a test category waste container intended for shipment in the Transuranic Package Transporter-II (TRUPACT-II). The phrase "gas generation testing" shall refer to any activity that establishes the flammable gas concentration or the flammable gas generation rate. This includes, but is not limited to, measurements performed directly on waste containers or during tests performed on waste containers. This Quality Assurance Program Plan (QAPP) documents the quality assurance (QA) and quality control (QC) requirements that apply to the Program. The TRUPACT-II requirements and technical bases for allowable flammable gas concentration and gas generation rates are described in the TRUPACT-II Authorized Methods for Payload Control (TRAMPAC) (Reference 1).

\subsection{PROGRAM DESCRIPTION}

This section describes the Program organization, the scope of the Program, and the data quality controls required for the Program. The minimum requirements for Program participants are specified throughout this document by the use of the terms "shall," "will," or "must." All U.S. Department of Energy (DOE) sites participating in the Program shall meet the requirements of this QAPP.

\subsection{Program Organization}

This section describes the roles and responsibilities of the participants in the Program. The Program participants include the DOE-Carlsbad Field Office (CBFO) and participating DOE sites.

\subsubsection{DOE-CBFO}

The DOE-CBFO is responsible for the overall management of the Program and for review and approval of implementing documents.

\subsubsection{Participating DOE Sites}

The DOE sites that perform gas generation testing under a QA program that has been audited pursuant to the requirements of this QAPP and the DOE Quality Assurance Program Document (QAPD) (Reference 2) will be considered compliant. Sites performing gas generation tests are responsible for establishing site programs in compliance with the Program, as documented in a site-specific quality assurance project plan (QAPjP) that provides detailed and comprehensive guidance to effectively implement the applicable QA and QC requirements of this QAPP and the DOE QAPD. The QAPjPs will be submitted to the DOE-CBFO for review and approval. The QAPjPs shall include or be supplemented by standard operating procedures, work plans, or work instructions that include detailed instructions for maintaining quality while performing Program tasks. The Program organization at each participating site shall, at a minimum, consist of the following (Note: Multiple job titles may be held by a single person to meet site-specific needs). 


\subsubsection{GGTP Manager}

The GGTP Manager shall be responsible for the operation and maintenance of the gas generation test apparatus and the management of the data generated from GGTP operations.

\subsubsection{GGTP Technical Supervisor}

The GGTP Technical Supervisor assists the GGTP Manager in the coordination of GGTP operations and shall document any nonconformances in testing operations.

\subsubsection{GGTP Independent Technical Reviewer}

The GGTP Independent Technical Reviewer shall be responsible for performing technical reviews of GGTP batch reports prior to transmittal to the GGTP QA Officer.

\subsubsection{GGTP QA Officer}

The GGTP QA Officer shall be responsible for the review of GGTP testing data, GGTP batch reports, and nonconformance documentation.

\subsection{Program Scope}

The Program, as described in this QAPP and the TRAMPAC, defines the gas generation testing requirements for the qualification of contact-handled transuranic test category waste.

\subsection{Program Data Quality Controls}

\subsubsection{Data Quality Objectives}

The data quality objectives (DQOs) for the Program are as follows:

- Total Gas Generation Rate - For Waste Type III with decay heat greater than 7 watts and Waste Type IV, establish the total gas generation rate in the waste container. This information will be used to evaluate compliance with the allowable total gas generation rate for a waste container that cannot be shown to be compliant by conservative theoretical analysis.

- Hydrogen/Methane Gas Generation Rate - Establish the gas generation rate of hydrogen and methane in the waste container. This information will be used to assess compliance with the limits on the flammable gas generation rate for a waste container.

- Flammable Volatile Organic Compound (VOC) Concentration - If the flammable VOC concentration cannot be shown through acceptable or process knowledge to be less than or equal to 500 parts per million (ppm) by volume, establish the headspace concentration of flammable VOCs in a waste container. This information will be used to assess compliance with the limits on the flammable gas in the waste container.

\subsubsection{Quality Assurance Objectives}

The quality assurance objectives (QAOs) specified in this QAPP establish minimum requirements for the measurement and representation of DQOs. The elements of the DQOs are: precision, accuracy, 
representativeness, completeness, and comparability. These elements are defined in the Definition section of this plan.

\subsection{QUALITY REQUIREMENTS}

The DOE QAPD describes and establishes the DOE-CBFO QA program and identifies the sources of all applicable QA requirements. Sites performing gas generation testing in support of compliance determinations for TRUPACT-II transportation shall demonstrate compliance under the DOE-CBFO QA program that is consistent with Title 10, Code of Federal Regulations, Part 71 (10 CFR 71), Subpart H, Quality Assurance. Sites performing this work that have been audited per the requirements of the DOE QAPD will be considered compliant. The GGTP QAPP is a subset of the comprehensive QA program to meet the requirements of the DOE QAPD and is specific only to the performance of the gas generation testing. As such, the quality requirements discussed in this document are limited to those that apply to the activities associated with gas generation testing. This section identifies the minimum required documentation for sites participating in the Program.

\subsection{Records}

Sites shall maintain sufficient written records to describe the project activities identified as a NCR and a TRU waste program. The records must include the QAPjP and the instructions and procedures required to prescribe $Q A$ activities and related specifications, such as required qualifications of procedures and equipment. The records must include instructions or procedures establishing a records retention program that designates factors such as duration, location, and assigned responsibility. The site shall retain the QA records for a minimum of three years after containers covered by these records have been shipped.

\subsection{Training}

Personnel shall be trained and qualified to ensure they are capable of performing their assigned tasks and to ensure that job proficiency is maintained. All personnel involved in the Program shall be trained in accordance with site-specific training methodology. The training and qualification requirements for each of the positions shall be documented and shall be commensurate with the function each is to perform.

\subsection{Procurement}

The design bases and other requirements necessary to ensure adequate quality shall be included or referenced in procurement documents for any equipment and services affecting quality. Site-specific procedures, as approved by the CBFO QAPD audit process, shall ensure compliance with procurement document requirements through supplier qualification/receipt inspection.

\subsection{Software}

Any software used in data collection or reduction shall be qualified under a site-specific software QA program. Evaluation and qualification of software under site-specific procedures, as approved by the CBFO QAPD audit process, shall be documented. 


\subsection{GGTP DATA MEASUREMENT OR DETERMINATION}

The criteria for selection of the waste containers for the Program and the waste parameters that must be characterized prior to the test are described in the TRAMPAC. The site shall also verify that the waste meets one of the definitions of test category waste, as follows:

- The waste container decay heat exceeds analytical limit

- The waste type has no bounding $G$ value

- The flammable VOC concentration in container headspace cannot be demonstrated to be less than or equal to $500 \mathrm{ppm}$.

A parameter, e.g., void volume, required to determine gas generation rates may be estimated, instead of measured, if it can be shown that the use of the estimated parameter value will result in a conservative (higher) calculated gas generation rate than that calculated using a measured parameter value. Sites shall maintain records that document that the parameter estimation is conservative and has been approved by DOE-CBFO for use in gas generation testing. Methane gas sampling and analysis shall be required to meet DQOs in cases where the methane generation rate is not accounted for by theoretical analysis (see Section 4.2). ${ }^{a}$ Validated gas sampling and analysis data and results for a given container remain valid if the container is opened unless the container contents have been changed. If container contents have been changed and gas sampling or testing data are required, the data must be obtained again.

\subsection{Flammable VOC Concentration in Container Headspace}

If it cannot be established through acceptable or process knowledge that the flammable VOC concentration in the container headspace is less than or equal to $500 \mathrm{ppm}$ by volume, the headspace gas shall be sampled and analyzed to determine the flammable VOC concentration. Measurement of flammable VOCs is part of the Program because of their contribution to the flammability potential within the container. Sites shall be responsible for ensuring that containers have reached an acceptable equilibrium condition prior to container testing, as defined in the TRAMPAC.

${ }^{a}$ The derivation of conservative G values in the TRUPACT-II Safety Analysis Report shows that for Waste Type I (solidified inorganic waste) there is no methane generation. For Waste Types II and III, a conservative estimate for the methane generation rate is $2.5 \%$ of the hydrogen generation rate ( $\mathrm{G}$ value of 0.1 versus 4$)$. If methane is not sampled for, a value of $2.5 \%$ of the hydrogen generation rate or hydrogen concentration must be added in determining compliance with the limits. For Waste Type IV, the methane generation rate can be estimated by multiplying the methane-to-hydrogen concentration ratio measured in the container headspace at ambient conditions and the hydrogen generation rate established from container testing. 


\subsection{Gas Generation Rates}

A process shall be developed to establish the generation rate of hydrogen, methane, or total gas in a waste container. Allowable processes for establishing gas generation rates, as specified in the TRAMPAC, may consist of measurement of waste container headspace concentrations or container testing. Procedures for each process, including allowable operating temperatures, are described in the TRAMPAC. Each site shall prepare a test standard operating procedure, as approved by the CBFO QAPD audit process, describing site-specific implementation of the procedures in the TRAMPAC. Any combination of hardware and software that collects data that meets the QAOs listed in Section 4.3 may be used. Site-specific testing procedures, as approved by the CBFO QAPD audit process, must ensure that hydrogen recombiners or getters are not present during any process designed to establish gas generation rates.

\subsection{Quality Assurance Objectives}

All measured parameters must comply with the QAOs listed in this section.

\subsubsection{Precision and Accuracy}

The QAO for precision of the measured or calculated hydrogen/methane and total gas generation rates shall be less than or equal to a relative percent difference of 25 percent. The QAO for accuracy of the measured or calculated hydrogen/methane and total gas generation rates shall be between 70 to 130 percent recovery. In the case where a gas generation rate is not measured directly but calculated from knowledge of other measured or estimated parameters, the requirements of precision and accuracy listed above shall be met as demonstrated through an error propagation analysis.

For a specific DOE site, the program-required quantification limits (PRQLs) for hydrogen/methane and total gas generation rates shall be specified as no higher than the respective lowest allowable generation rate of waste to be shipped from that site. The site must have the capability to quantify the gas generation rates at the PRQLs.

\subsubsection{Representativeness}

In order to ensure representativeness of gas samples, leak tests or system monitoring shall be performed on the test and gas-sampling systems in accordance with site-specific requirements that have been approved by CBFO.

\subsubsection{Completeness}

All waste containers in which the flammable VOC concentration cannot be shown through acceptable knowledge or process knowledge to be less than or equal to $500 \mathrm{ppm}$ by volume shall have a valid gas sample collected and analyzed to establish the flammable VOC concentration.

Containers that undergo gas generation testing shall have valid parameter measurements to establish the hydrogen and methane gas generation rates in the container. 
All containers where compliance with the total gas generation limits is not shown by conservative theoretical analysis in accordance with the TRAMPAC shall have valid parameter values to establish the total gas generation rate.

\subsubsection{Comparability}

Comparability of data shall be ensured through the use of standardized, approved testing, sampling, and analytical techniques. Consistent use and application of uniform procedures, calibration of analysis instruments against nationally acceptable (traceable to NIST) or manufacturer-certified standards, and use of instruments that are of the required precision and accuracy should ensure data measurements on different waste containers are comparable.

\subsection{QC Requirements for Program Sampling and Analysis}

To ensure that data of known and documented quality are produced from the Program gas sampling and analysis procedures, laboratory personnel collecting gas samples from containers shall comply with sitespecific $Q C$ requirements for additional samples within a sampling batch. A batch is defined on a sitespecific basis and shall be statistically defensible.

\subsection{Equipment Testing, Inspection, and Maintenance Requirements}

Site-specific procedures shall be developed to control the use, testing, inspection, handling, storage, maintenance, and calibration of measuring and test equipment.

\subsection{DATA MANAGEMENT, REDUCTION, REVIEW, VALIDATION, AND REPORTING}

\subsection{Data Management}

Prior to Program testing, a container selection process is performed as described in the TRAMPAC. The selection process shall compile the following container information:

- Container number

- Packaging date (if applicable)

- Wattage

- Date of last headspace disturbance (if applicable)

- Preliminary shipping category.

The container shall then be prepared for gas generation testing in accordance with the site-specific procedure(s). Site-specific procedures shall detail the steps of pre-test, test, and post-test activities to ensure data quality and include instructions for tasks such as apparatus bolt torquing and leak testing, allowance for container equilibration times, measurement of temperature and pressure, void volume determination, scheduling of gas samples, maintenance of chain-of-custody forms for sample containers, and any task that the site determines appropriate. 
All measured test data shall be validated in accordance with site-specific plans or procedures that specify the acceptance criteria used to determine data validity, compliant with the requirements in the TRAMPAC, and shall indicate the personnel responsible for performing the data validation.

\subsection{Data Reduction}

If gas generation rate calculations are based on mathematical models of the waste container and the testing apparatus, the basis and assumptions used in the model shall be valid for the population of containers and testing equipment used. The mathematical model shall be checked by a knowledgeable subject matter expert for adequacy and accuracy. Program calculations and data reporting shall be performed in accordance with site-specific procedures, which shall conform with the methodology described in the TRAMPAC and compliant with the QAPD. The data calculation and reporting shall be verified and validated. The complete data package shall be assembled for independent review and validation in accordance with site-specific procedures.

\subsection{Data Review and Validation}

Data review and validation at the data generation level shall be reviewed by an independent reviewer and signature released from designated personnel such as the GGTP Technical Supervisor or the GGTP QA

Officer. These reviews shall be documented using appropriate checklists signed by the reviewer(s). The reviewed data, assembled as a data package (as defined by the sites to meet their individual needs), shall consist of the following at a minimum:

- Batch Data Reports - Testing and sampling batch data reports shall contain data reduced for reporting as required by the TRAMPAC.

- Proof of Independent Technical Review - The review checklist shall ensure that the characterization data have been collected and documented in accordance with the Program requirements. The review shall ensure that:

- Data generation and reduction are conducted in a technically correct manner in accordance with the method used.

- Data are reported in proper units and to the correct number of significant figures.

- Calculations are performed with a valid calculation program, or hand calculations have been independently checked.

- Data are reviewed for transcription errors.

- QA documentation is complete.

The GGTP Independent Technical Reviewer shall perform a technical review of the data. The GGTP Technical Supervisor or the GGTP QA Officer shall sign the package to confirm that the documentation is complete and that the QAOs have been met. 


\subsection{Data Reporting}

Site-specific procedures shall be developed to control data reporting to the DOE-CBFO. The report forms must include all of the information required in the test procedure, as well as signature releases to indicate document review and validation. The container testing data will be used to qualify the container for shipping and for preparing the payload shipping documentation. The batch data reports shall be identified with a unique identification number, and the pages shall be numbered with inclusive pagination.

\subsection{NONCONFORMANCES}

Nonconformance reports shall be generated in accordance with site-specific procedures. Suitable methods for segregation and disposition of failed containers shall be identified and documented. 


\subsection{REFERENCES}

U.S. Department of Energy (DOE), 2001. TRUPACT-II Authorized Methods for Payload Control (TRAMPAC), NRC Docket No. 71-9218, Revision 19 (May 2001), U.S. Department of Energy, Carlsbad Field Office, Carlsbad, New Mexico.

U.S. Department of Energy (DOE), 1999. Quality Assurance Program Document, CAO-94-1012, Revision 3, U.S. Department of Energy, Carlsbad Field Office, Carlsbad, New Mexico. 